\title{
Variability in abundance of algae and invertebrates at different spatial scales on rocky sea shores
}

\author{
Lisando Benedetti-Cecchi*
}

Dipartimento di Scienze dell'Uomo e dell'Ambiente, University of Pisa, Via A. Volta 6, 56126 Pisa, Italy

\begin{abstract}
Analyses of spatial pattern in populations and assemblages along distinct environmental gradients are common in ecology. Few studies have examined whether these patterns are consistent at a hierarchy of spatial scales, despite increasing evidence indicating that spatial variability is not scale independent. In this study I have investigated the general model that much of the variation on rocky sea shores occurs across the vertical gradient, unless major physical attributes of the habitat change. This model was contrasted with 2 alternative models that incorporate patchiness at different scales: either vertical variation is larger than horizontal variability at small but not at large scales of horizontal spatial variability or there is no characteristic scale at which vertical variation is larger than horizontal variability. In order to distinguish among these alternatives, I compared variability in abundance of organisms across heights on the shore on rocky coasts in the north-west Mediterranean, with estimates of horizontal variability obtained at different scales, ranging from the scale of the patch (among quadrats 10s of $\mathrm{cm}$ apart) up to the regional scale (among shores 100s of $\mathrm{km}$ apart). Results indicated that vertical and horizontal variability were comparable in magnitude at the smallest spatial scale, while horizontal variability was generally larger when measured at scales of $100 \mathrm{~s}$ to $1000 \mathrm{~s}$ of $\mathrm{m}$. When multivariate patterns in the structure of assemblages were examined, there was more vertical than along-shore variation at small $(10 \mathrm{~s}$ to $100 \mathrm{~s}$ of $\mathrm{cm}$ ) but not at large $(>1000$ s of $\mathrm{m}$ ) spatial scales. Univariate and multivariate analyses also revealed that much of the horizontal variation was among quadrats $10 \mathrm{~s}$ of $\mathrm{cm}$ apart. These results indicated that any description of spatial pattern in abundance for organisms living on rocky sea shores in the NW Mediterranean must contemplate both vertical and horizontal sources of variation, regardless of the scale investigated. It is concluded that failure to recognise the importance of sources of variation other that those expressed by the most obvious gradients detracts from potentially important causal processes hindering progress in ecological understanding.
\end{abstract}

KEY WORDS: Ecological models · Environmental gradients $\cdot$ Hierarchical analyses $\cdot$ Spatial scale Spatial variability $\cdot$ Rocky shores $\cdot$ Algae $\cdot$ Invertebrates

\section{INTRODUCTION}

There is increasing evidence from different areas of ecology indicating that patterns in nature are not scale independent (Dayton \& Tegner 1984, Menge \& Olson 1990, Levin 1992, Wiens et al. 1993, Schneider 1994, Wu \& Loucks 1995). Natural populations fluctuate in density at some scales in space and time more than at

\footnotetext{
*E-mail: bencecc@discat.unipi.it
}

others (e.g. Gaston \& McArdle 1993). As a consequence, changes in the composition and structure of assemblages are also more evident at particular scales (Underwood \& Chapman 1996). Although natural variability is often viewed as an impediment to ecological understanding, identifying the relevant scales of variation for populations and assemblages is central to the issues of prediction and explanation in ecology (Levin 1992). Knowledge of the spatial and temporal context within which repeatable patterns occur can increase 
the precision of ecological predictions significantly (Benedetti-Cecchi 2000). Because different processes are likely to generate variability at different scales, explanation of pattern may be facilitated by knowledge of the spatial and temporal scales where variation occurs (Underwood \& Chapman 1996).

The paradigm of pattern and scale in ecology has resulted in significant theoretical and empirical development. It is maintained that different perspectives on the structure and organisation of assemblages, such as the equilibrium versus non-equilibrium dichotomy, determinism versus stochasticity in ecological succession, contingency versus generalisation in biological interactions, can be reconciled by defining the appropriate spatial and temporal scales to which ecological models apply (McCook 1994, Wu \& Loucks 1995). Studies in terrestrial and aquatic environments have illustrated how the scale of observation influences the description of pattern and how ecological complexity prevents simple generalisations and dichotomous thinking (Rossi et al. 1992, Zhang \& Sanderson 1997, Carrol \& Pearson 1998, Hewitt et al. 1998, Rakocinski et al. 1998, Lapointe \& Bourget 1999, Thrush 1999). The integration of different scales in tests of hypotheses about spatial and temporal patterns poses methodological limits that are challenged by the continuous development of univariate and multivariate statistical procedures (Rossi et al. 1992, Cressie 1993, Underwood \& Chapman 1996, 1998, Legendre \& Anderson 1999, Anderson in press).

There are 2 main approaches to the analysis of spatial pattern in ecology with reference to the sources of variation investigated. Traditionally, studies have examined patterns of variation in populations and assemblages along environmental gradients (Borcard et al. 1992, Bell et al. 1993, Horne \& Schneider 1995, Hoagland \& Collins 1997). This is a profitable strategy because once a pattern is detected a search for causal processes can proceed by first focusing on the environmental variables that generate the gradient. This should facilitate the identification of the relevant experiments that need to be done in order to explain the pattern. There is, however, a problem with this approach in that it can bias the analysis toward the most obvious gradients, while other less evident, but potentially important sources of variation might go undetected. The alternative approach of investigating patterns at a range of spatial scales addresses this issue. With multi-scale analyses, random sources of variation are examined at a hierarchy of spatial scales and estimates of variance components allow comparison of variability across these scales (Greig-Smith 1952, Underwood \& Petraitis 1993, Horne \& Schneider 1995, Underwood 1996). These analyses encompass a wide range of processes that may be important to organisms, regardless of whether specific models about relevant processes can be proposed or not. The 2 approaches, however, are not mutually exclusive. Indeed, their integration is a logical requirement in any analysis of variability along environmental gradients. Detecting differences among strata in these analyses requires proper estimation of natural variability within strata to avoid problems of spatial confounding (Hurlbert 1984). Furthermore, testing whether a given pattern is consistent across a range of spatial scales can broaden the scope of a study, providing a test of the generality of models for the distribution and abundance of organisms. Despite the potential importance of these procedures, very few studies have examined whether or not patterns along distinct environmental gradients are consistent at a range of spatial scales.

Many studies on rocky coasts have focused attention on the vertical patterns of distribution (zonation) of organisms in response to the major gradient of emersion and desiccation (Stephenson \& Stephenson 1949, Southward 1958, Lewis 1964). These studies described broad-scale patterns along the vertical gradient of the shore, and their modification by wave action along the shore. The apparent ubiquity of these patterns stimulated a large number of experimental studies on the processes maintaining the vertical distribution of populations and assemblages on rocky coasts (reviewed in Underwood 1985, Hawkins et al. 1992). These analyses elucidated the effects of predation, herbivory, competition and physical factors in maintaining vertical patterns, providing much of our current understanding of the causes of spatial distribution of organisms on rocky shores.

More recently, however, there have been studies documenting considerable small-scale spatial variation (patchiness) within particular heights on the shore, and variation from shore to shore which is unrelated to differences in wave action or changes in other physical attributes of the habitat (Hartnoll \& Hawkins 1985, Foster 1990, Archambault \& Bourget 1996, Schoch \& Dethier 1996, Underwood \& Chapman 1996, Benedetti-Cecchi \& Cinelli 1997, Menconi et al. 1999). A number of processes have been invoked to explain these patterns, including variation in recruitment, the interactive effects of physical and biological factors, behavioural effects and small-scale changes in topography of the substratum (Underwood \& Chapman 1996, Benedetti-Cecchi et al. 2000a). The relative contribution of these processes to spatial variation remains largely unquantified, possibly reflecting a general lack of appreciation of the importance of horizontal variability due to the paucity of hierarchical analyses of spatial patterns on rocky coasts.

At least 3 models can be proposed to explain spatial patterns on rocky shores (Table 1). The first is that ver- 
tical variability is always larger than horizontal variability unless exposure to waves or other major physical attributes of the habitat change sharply. This model is supported by observational and experimental studies emphasising variation along environmental gradients (see above). Two additional models can be proposed to incorporate patchiness at different scales. Either vertical variation is larger than horizontal variability at small but not at large spatial scales or there is no characteristic scale at which vertical variation is larger than horizontal variation.

The main objective of the present study was to discriminate among these models by testing their proximate predictions (Table 1). The first model predicts significantly larger estimates of vertical than horizontal variability irrespective of the scale at which horizontal variation is measured. The second model predicts larger estimates of vertical than horizontal variability at small spatial scales, with differences reducing as the scale at which horizontal variability is measured increases. Finally, the third model predicts no clear pattern in the differences between vertical and horizontal variability. In order to test these hypotheses, I compared variation in the distribution of organisms across heights on the shore on rocky coasts in the north-west Mediterranean, with estimates of horizontal variability in abundance obtained at different scales, ranging from the scale of the patch (among quadrats $10 \mathrm{~s}$ of $\mathrm{cm}$ apart) up to the regional scale (among shores 100s of $\mathrm{km}$ apart). In addition to providing a test for the models above, these analyses also tested the general hypothesis that spatial patterns were invariant with scale. Rejection of this hypothesis would lead to the identification of the relevant scales of variation for the populations and assemblages investigated.

\section{MATERIALS AND METHODS}

Study locations. This study was done between January and May 1997 at 3 localities in the north-west Mediterranean: Calafuria, a few kilometres south of Livorno, Italy $\left(43^{\circ} 30^{\prime} \mathrm{N}, 10^{\circ} 20^{\prime} \mathrm{E}\right)$; Capraia, an island offshore from Livorno $\left(43^{\circ} 02^{\prime} \mathrm{N}, 9^{\circ} 50^{\prime} \mathrm{E}\right)$, and Punta Bianca, about $70 \mathrm{~km}$ north of Livorno $\left(44^{\circ} 05^{\prime} \mathrm{N}\right.$, $\left.9^{\circ} 59^{\prime} \mathrm{E}\right)$. These localities provided 1 out of several possible sets of shores that might have been used to represent assemblages on rocky sea shores in the north-west Mediterranean. All shores were exposed to wave action and consisted of gently sloping $\left(<25^{\circ}\right)$ rocky benches 15 to $50 \mathrm{~m}$ long and 2 to $10 \mathrm{~m}$ wide, interspersed among areas of substratum of variable slope and inaccessible rocky cliffs. The substratum was sandstone at Calafuria, it was mostly volcanic at Capraia, and schists and calcareous rocks occurred at Punta Bianca. Although the Mediterranean is characterised by narrow tidal ranges (the average amplitude of the tide is about $25 \mathrm{~cm}$ in the study region), organisms can extend their vertical range of distribution above the limits of the tide due to the effects of wave action and changes in sea level due to barometric pressure (Menconi et al. 1999). The influence of wave action and barometric pressure on sea level can be greater than that of the tide in this microtidal environment.

The 3 shores supported qualitatively similar assemblages of algae and invertebrates. Assemblages changed with height on the shore, although patterns of change could differ from shore to shore (Menconi et al. 1999, Benedetti-Cecchi et al. 2000a,b). In general, the tops of the shores were dominated by the barnacle Chthamalus stellatus (Poli), the littorinid snail Melaraphe neritoides (Linné) and cyanobacteria (mostly Rivularia spp.). The most common organisms at mid-shore

Table 1. Predictions from alternative models explaining spatial variability in abundance of organisms on rocky shores $\left(K^{2}\right.$ vertical vertical variability in abundance; $\sigma_{\text {horizontal, }}^{2}$ horizontal variability in abundance)

\begin{tabular}{|c|c|c|}
\hline Observations & Models & Predictions \\
\hline $\begin{array}{l}\text { Many studies have shown that physical and } \\
\text { biological processes operate on rocky coasts } \\
\text { to maintain heterogeneity in assemblages } \\
\text { across the vertical gradient of the shore. } \\
\text { These observations lead to Model } 1\end{array}$ & $\begin{array}{l}\text { (1) Vertical variability is always larger } \\
\text { than horizontal variability unless exposure } \\
\text { to waves or other major physical attributes } \\
\text { of the habitat change }\end{array}$ & $\begin{array}{l}K^{2} \text { vertical }>\sigma_{\text {horizontal }}^{2} \text { irrespective of the spatial } \\
\text { scale at which horizontal variability is } \\
\text { measured }\end{array}$ \\
\hline $\begin{array}{l}\text { In addition to variability across the vertical } \\
\text { gradient, there is considerable patchiness in } \\
\text { the structure of assemblages within heights on } \\
\text { the shore, and differences from shore to shore } \\
\text { that are unrelated to macroscopic changes in } \\
\text { the physical features of the habitat. These } \\
\text { observations can be explained with either } \\
\text { Model } 2 \text { or Model } 3\end{array}$ & $\begin{array}{l}\text { (3) There is no characteristic scale (or } \\
\text { range of scales) at which vertical variability } \\
\text { is larger than horizontal variability }\end{array}$ & $\begin{array}{l}K_{\text {vertical }}^{2}>\sigma_{\text {horizontal }}^{2} \text { at small spatial scales with } \\
\text { differences decreasing as the scale at which } \\
\sigma_{\text {horizontal }}^{2} \text { is measured increases and possibly } \\
\sigma_{\text {horizontal }}^{2}>K_{\text {vertical }}^{2} \text { at large spatial scales } \\
\sigma_{\text {horizontal }}^{2} \geq K_{\text {vertical }}^{2} \text { at any scale }\end{array}$ \\
\hline
\end{tabular}


heights were barnacles, cyanobacteria, the fleshy red algae Rissoella verruculosa (Bertolini) J. Agardh and Nemalion helmintoides (Valley in Withering) Batterns, the filamentous algae Chaetomorpha aerea (Dillwyn) Kützing and Polysiphonia sertularioides (Grateloup) J. Agardh, some unidentified encrusting corallines, the brown encrusting alga Ralfsia verrucosa (Areshough) J. Agardh, the limpets Patella rustica Linné and $P$. aspera Röding and the topshell Osilinus turbinatus (Von Born). Low-shore habitats were characterised mainly by turf-forming algae (consisting of several species of articulated coralline, coarsely branched and filamentous algae), canopy-forming algae of the genus Cystoseira, encrusting corallines, including the encrusting base of Corallina elongata (Ellis et Solander) and the mussel Mytilus galloprovincialis Lamark. The limpets $P$. aspera Röding, and P. caerulea Linné were common in patches of bare rock or over encrusting coralline algae in low-shore habitats.

In addition to these general patterns of distribution, there was also considerable variation among patches of substratum within heights on the shore (BenedettiCecchi et al. 1999, Menconi et al. 1999). Patchiness originated from the effects of physical disturbance (wave action and stress due to desiccation) and differences in patterns of recolonisation of disturbed patches due to the interactive effects of variable recruitment, grazing and pre-emption of the substratum (BenedettiCecchi et al. 1999, Benedetti-Cecchi 2000). Furthermore, there can be considerable microhabitat variation on these shores due to the complex topography of the substratum (Benedetti-Cecchi et al. unpubl. data).

Sampling design. Twelve sites (stretches of coast 10 to $15 \mathrm{~m}$ long) were selected randomly on each shore from areas of gently sloping substrata exposed to wave action. Shores faced west or south-west and were exposed to the same prevailing winds. Sites were distributed along 4 to $5 \mathrm{~km}$ of coastline and were chosen to represent the assemblages present on each shore. Two patches of substratum 1.5 to $2 \mathrm{~m}$ long and 3 to $12 \mathrm{~m}$ apart were selected randomly in each site. Four tidal heights were sampled in each patch using 3 random quadrats per height. Tidal heights were chosen to represent vertical variation in abundance of plants and animals between 0 and $0.4 \mathrm{~m}$ above the mean-low-water-level (MLWL), and corresponded approximately to $0,15,20$ and $35 \mathrm{~cm}$ above the MLWL. Patches were 1.5 to $2 \mathrm{~m}$ wide (up-shore), depending on the slope of the substratum, so that vertical and horizontal variation was sampled at the same spatial scale within each patch. Tidal heights were established at each site using staffs and a spirit level during calm days, as predicted from tide tables (Istituto Idrografico della Marina 1995), after correcting for the effect of barometric pressure.
Organisms were sampled in quadrats of $15 \times 10 \mathrm{~cm}$, with the longer axis of the plot placed parallel to the shore. The quadrat was divided into 24 sub-quadrats of $2.5 \times 2.5 \mathrm{~cm}$. Percent cover values of sessile organisms (algae and invertebrates) were determined visually (Dethier et al. 1993, Benedetti-Cecchi et al. 1996) by assigning to each taxon a score ranging from 0 to 4 and adding up the 24 estimates. Final values were expressed as percentages. Densities of mobile gastropods were expressed as number of individuals per plot.

It was not possible to sample all the 12 sites on each shore (i.e. 288 quadrats) in just 1 sampling occasion. To avoid the problem of sampling assemblages on different shores at different times, and to provide estimates of small-scale temporal variability for these assemblages, I independently sampled each shore twice between January and May 1997. Each shore was assigned to 2 sampling dates chosen randomly within the study period, so that shores were properly interspersed in time. Six of the 12 sites (chosen randomly) for each shore were sampled on date 1, and the remaining sites were sampled on date 2. Sampling was completed within 2 to $3 \mathrm{~d}$ at each date.

Analysis of data. I used univariate analysis of variance (ANOVA) to test the null hypothesis that patterns in abundance of individual species, or groups of morphologically similar species, did not change significantly in time, a necessary assumption to test hypotheses about patterns in spatial variability (see below). This was a reasonable expectation given the short temporal scale of the investigation and the results of previous studies indicating that temporal variability was negligible in winter and spring for these assemblages (Benedetti-Cecchi et al. 1999, Menconi et al. 1999, Benedetti-Cecchi 2000). The design consisted of 5 factors: Shores (3 levels), Dates (2 levels, nested in Shores), Sites (6 levels, nested in Dates and Shores), Patches (2 levels, nested in Sites, Dates and Shores), and Height (4 levels, orthogonal to all the other factors). Height was a fixed factor in the analyses, whereas all the other factors were random. The tests of interest were the Height $\times$ Date(Shore) interaction and, if this was not significant, the main effect of Date.

Testing the proposed models about patterns in spatial variation (Table 1) required the comparison of vertical variability with estimates of horizontal variance measured at increasing spatial scales. Horizontal variance was measured at the scale of the patch (variability among quadrats $10 \mathrm{~s}$ of $\mathrm{cm}$ apart), the scale of the site (measuring variation among quadrats plus the variability among patches some metres apart), the scale of the shore (including variation among quadrats, patches and sites $10 \mathrm{~s}$ to $1000 \mathrm{~s}$ of $\mathrm{m}$ apart), and the regional scale (including variability among quadrats, 
patches, sites and shores $100 \mathrm{~s}$ of $\mathrm{km}$ apart). In order to make these comparisons, the 12 sites sampled on each shore were divided randomly in 4 groups of 3 sites each. Each group was used to compare vertical and horizontal variability at a particular scale. For example, 3 sites from each shore were available to compare variability in abundance of a particular species across heights on the shore, with variability among quadrats within heights (i.e. variability at the scale of the patch). I used 1-way ANOVAs independently for each patch to estimate the variability among quadrats within heights (the residual of the analysis), and the variation among heights (Fig. 1a). This was obtained by equating the observed mean square for factor height to the expected mean square derived from the linear model of the analysis (see Winer et al 1991 and Underwood 1997 on how to derive expected mean squares for any given design). In this case, an estimate of vertical variability was simply obtained as $\left(\mathrm{MS}_{\text {height }}-\mathrm{MS}_{\text {residual }}\right) / n$, where $n$ is the number of replicate quadrats within heights $(n=3)$. This procedure resulted in independent estimates of vertical and horizontal variability for each patch, given the properties of ANOVA (Searle et al. 1992, Underwood 1997). There were 18 patches available for this analysis ( 3 shores $\times 3$ sites $\times 2$ patches), giving 18 estimates for each of the 2 types of variability (vertical and horizontal).

Another set of 3 sites from each shore was used to compare vertical variability with estimates of horizontal variance at the scale of the site (Fig. 1b). Replicate quadrats were first pooled across patches for each height. The resulting 6 quadrats were then divided randomly into 2 groups of 3 quadrats each. This procedure was repeated for every height in order to obtain 2 sets of data, each consisting of 3 replicate quadrats for each of the 4 heights considered. In this case horizontal variability measured variation among quadrats plus the variation due to the patches (variability at the scale of the site). Again, 1-way ANOVAs were used independently for each set of data to obtain 2 replicate estimates of vertical and horizontal variability from each site. There were 9 sites available for these analyses ( 3 shores $\times 3$ sites), giving 18 estimates for each of the 2 types of variability.

Following this procedure, I used the remaining 2 sets of 3 sites on each shore to compare vertical variation with estimates of horizontal variability at the scale of the shore and at the regional scale, respectively. Horizontal variability measured at the scale of the shore estimated the variance among quadrats plus that among patches and among sites. At the regional scale, horizontal variability measured the sum of the variability among quadrats, patches, sites and shores. There were 18 independent estimates for each of the 2 types of variability at each of these scales.
Large temporal variation in assemblages could confound the comparison of vertical and horizontal variation because sites sampled at different times were pooled to estimate spatial variability. Temporal variation was, however, negligible in the present study (see 'Results'). As a consequence, I proceeded with the comparison of vertical and horizontal variability at increasing spatial scales using 2-way ANOVAs with the following factors: Type of variability, with 2 levels (vertical and horizontal variation, fixed); and Scale, with 4 levels (patch, site, shore and region, fixed). There were 18 independent estimates of variation within each combination of the 2 factors.
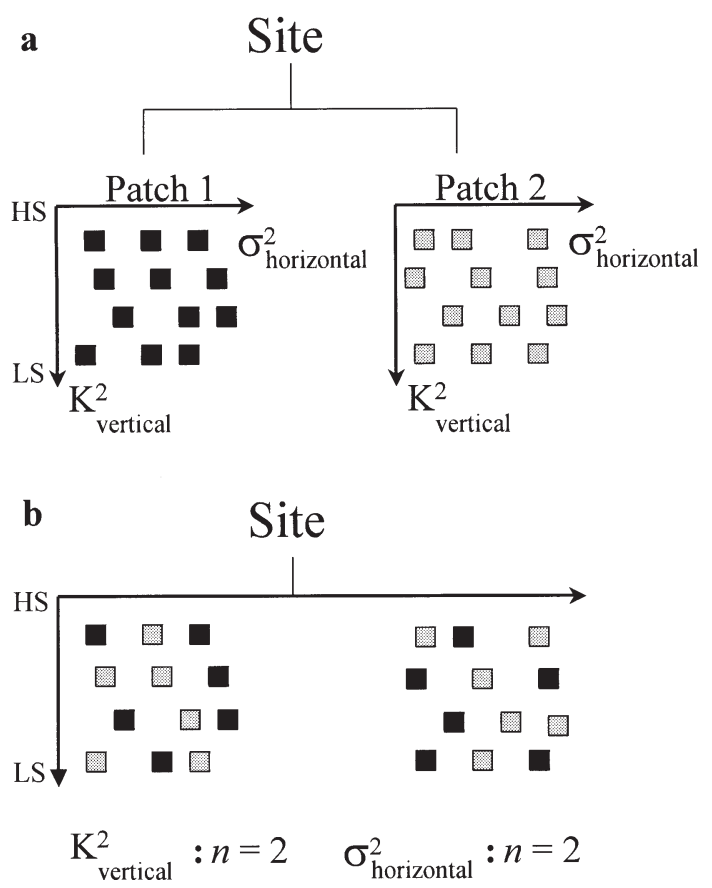

Fig. 1. Illustration of the arrangement of sampling units within patches and patches within sites. There were 3 sites on each shore to compare vertical and horizontal variability at a particular scale of horizontal spatial variation. Scales examined: patch (variability among quadrats), site (variability due to quadrats and patches), shore (variability due to quadrats, patches and sites), and region (variability due to quadrats, patches, sites and shores). (a) One-factor ANOVA repeated separately for each patch to obtain 2 replicate estimates of vertical and horizontal variation at scale of the patch from a site. (b) Two sets of data created to measure horizontal variation at scale of the site. This was done by randomising the 6 samples available for each height on shore (3 from each patch) in 2 groups of 3 quadrats each (black and grey symbols), and using separate ANOVA for each group to obtain 2 replicate estimates of vertical and horizontal variation at scale of the site from a site. By extension, the procedure was used to measure horizontal variability at scale of the shore and at the regional scale. HS: high shore; LS: low shore. See text for further details 
Cochran's $C$ test was used to check the assumption of homogeneity of variances before using ANOVA in tests of hypotheses. When necessary, data on abundance were either arcsine- or log-transformed prior to analysis, while data on vertical and horizontal variability were always log-transformed to remove heterogeneity. In some cases transforming the data was not sufficient to achieve homogeneity of variances (see 'Results'). When this occurred, I proceeded with the analyses anyway because ANOVA is robust to deviations from the assumption of homogeneity of variances when there are many independent estimates of residual variability, and because non-significant effects can still be interpreted when homogeneity is not met (Underwood 1997). In contrast to hypothesis testing, homogeneity of variances is not required when ANOVA is used for estimating parameters (Winer et al. 1991, Underwood 1997). Therefore, I did not check this assumption for analyses on vertical and horizontal variation. Occasionally, negative estimates of variances were obtained. In these cases variances were set to zero, under the assumption that they were sample underestimates of small or zero variances (Searle et al. 1992, Burdick \& Gaybrill 1992, Underwood 1996). When appropriate, SNK tests were used for multiple comparisons of the means (at $\alpha=0.05$ ). All univariate analyses were done using the GMAV5 programme (courtesy of A. J. Underwood \& G. Chapman, University of Sydney, Australia).

Multivariate techniques, based on non-parametric multivariate analysis of variance (NPMANOVA, Anderson 2001), were used to estimate vertical and horizontal variation in assemblages. These analyses tested the same hypotheses outlined above (Table 1), but in a multivariate context. The procedure is based on the semi-metric Bray-Curtis measures of dissimilarity (Bray \& Curtis 1957), which is used to calculate a matrix of distances between pairs of samples. The total (multivariate) variation in a set of samples expressed by these distances is then partitioned in within-group and among-group sums of squares in a way comparable to the additive partitioning of variation in univariate ANOVA (Anderson 2001, McArdle \& Anderson 2001). The resulting mean squares can therefore be equated to the expected mean squares to estimate components of variation as in ANOVA. I applied the procedure to each of the 4 sets of data described above (1 for each scale of horizontal variability) to obtain estimates of vertical and horizontal multivariate variation. Estimates were obtained using the NPMANOVA programme (courtesy of M. J. Anderson, University of Auckland, New Zealand). Vertical and horizontal variation in assemblages were then compared using a 2-way ANOVA with Type of variation and Scale as fixed, orthogonal factors, as described for the univariate case.
In order to determine whether multivariate patterns were influenced by the taxonomic composition of assemblages, by changes in relative abundance of taxa or by both factors, these analyses were repeated using Bray-Curtis measures of dissimilarity obtained from abundance as well as presence/absence data.

\section{RESULTS}

Preliminary analyses indicated that temporal variation might have confounded estimates of spatial variability from sites sampled at different times for articulate corallines and Rissoella verruculosa. In both cases ANOVA indicated a significant Height $\times$ Date(Shore) interaction (articulate corallines: $\mathrm{MS}_{\text {effect }}$ $=1978.7, \mathrm{MS}_{\text {denominator }}=748.3, F_{9,90}=2.64, \mathrm{p}<0.01 ; R$. verruculosa: $\mathrm{MS}_{\text {effect }}=1563.4, \mathrm{MS}_{\text {denominator }}=509.9$, $\left.F_{9,90}=3.1, \mathrm{p}<0.005\right)$. Therefore, the confounding effect of temporal variability should be considered when comparing vertical and horizontal sources of variation for these organisms. In order to alleviate this problem, I used a restricted randomisation of sites to scales of horizontal variability within each date. That is, rather than randomising the 12 sites from each shore across the 4 spatial scales at which horizontal variability should be estimated, I randomised the 6 sites sampled at a particular date across 2 spatial scales (chosen randomly), and the remaining 6 sites were used to estimate horizontal variation at the remaining 2 scales. In this way, horizontal variability for articulate corallines and $R$. verruculosa was measured from samples collected on the same sampling occasion at all but the largest scale (the regional scale). This eliminated the problem of temporal confounding for contrasts of vertical and horizontal variability at 3 out of 4 spatial scales. Temporal variation could not be reduced for comparisons at the regional scale because different shores were sampled at different times. Therefore, results have been interpreted cautiously for articulated corallines and $R$. verruculosa when analyses involved spatial variability at the regional scale.

Two distinct outcomes were evident from the analysis of spatial variation in abundance of macroalgae (Fig. 2). The first involved significant Scale $\times$ Type of variability interactions, which occurred for most of the groups of algae investigated (Table 2). SNK tests within these interactions indicated that horizontal variability was always significantly larger than vertical variation at the scale of the shore and the regional scale (Fig. 2, Table 3). No significant difference between vertical and horizontal variability occurred at the scale of the patch, while at the scale of the site encrusting corallines displayed significantly more hor- 
Table 2. Two-way ANOVA comparing vertical and horizontal variability (Type of variability) at different spatial scales (Scale). Data were log-transformed prior to analysis. Homogeneity of variances (after Cochran's C-test) not achieved for Articulate coralline algae, encrusting corallines, Mytilus galloprovincialis, Patella aspera/caerulea and P. rustica

\begin{tabular}{|c|c|c|c|c|c|c|c|c|c|c|}
\hline \multirow[t]{2}{*}{ Source of variatio } & \multicolumn{3}{|c|}{$\begin{array}{l}\text { Scale } \\
(3 \mathrm{df})\end{array}$} & \multicolumn{3}{|c|}{$\begin{array}{c}\text { Type of } \\
\text { variability } \\
\text { (1 df) }\end{array}$} & \multicolumn{3}{|c|}{$\begin{array}{c}\text { Scale } \times \text { Type } \\
\text { of variability } \\
(3 \mathrm{df})\end{array}$} & \multirow{2}{*}{$\begin{array}{c}\text { Residual } \\
\text { (136 df) } \\
\text { MS }\end{array}$} \\
\hline & MS & $F$ & $\mathrm{p}$ & MS & $F$ & $\mathrm{p}$ & MS & $F$ & $\mathrm{p}$ & \\
\hline \multicolumn{11}{|l|}{ Algae } \\
\hline Articulate corallines & 2.432 & 0.7 & $>0.5$ & 28.138 & 8.3 & $<0.005$ & 19.922 & 5.9 & $<0.001$ & 3.387 \\
\hline Cyanobacteria & 6.680 & 1.8 & $>0.15$ & 15.059 & 4.0 & $<0.05$ & 13.976 & 3.7 & $<0.05$ & 3.732 \\
\hline Coarsely branched algae & 1.971 & 0.4 & $>0.5$ & 97.356 & 18.5 & $<0.001$ & 15.160 & 2.8 & $<0.05$ & 5.256 \\
\hline Cystoseira compressa & 1.600 & 0.6 & $>0.6$ & 39.877 & 13.6 & $<0.0005$ & 5.7730 & 2.0 & $>0.1$ & 2.927 \\
\hline Encrusting corallines & 4.265 & 1.5 & $>0.15$ & 183.639 & 65.8 & $<0.001$ & 11.877 & 4.2 & $<0.01$ & 2.787 \\
\hline Filamentous algae & 15.815 & 5.7 & $<0.001$ & 196.123 & 71.7 & $<0.001$ & 26.964 & 9.8 & $<0.001$ & 2.734 \\
\hline Ralfsia verrucosa & 2.204 & 0.8 & $>0.45$ & 76.512 & 29.0 & $<0.0001$ & 6.784 & 2.6 & $>0.05$ & 2.641 \\
\hline Rissoella verruculosa & 32.874 & 6.3 & $<0.001$ & 37.187 & 7.2 & $<0.01$ & 16.431 & 3.1 & $<0.05$ & 5.169 \\
\hline \multicolumn{11}{|l|}{ Invertebrates } \\
\hline Chthamalus spp. & 11.410 & 2.4 & $>0.05$ & 1.060 & 0.2 & $>0.35$ & 29.262 & 6.3 & $<0.001$ & 4.600 \\
\hline Mytilus galloprovincialis & 49.526 & 7.1 & $<0.001$ & 124.813 & 18.0 & $<0.001$ & 43.503 & 6.2 & $<0.001$ & 6.929 \\
\hline Patella aspera/caerulea & 0.398 & 2.0 & $>0.1$ & 6.316 & 32.0 & $<0.0001$ & 0.189 & 1.0 & $>0.4$ & 0.198 \\
\hline Patella rustica & 0.049 & 1.4 & $>0.2$ & 0.702 & 20.2 & $<0.0001$ & 0.046 & 1.3 & $>0.25$ & 0.035 \\
\hline
\end{tabular}

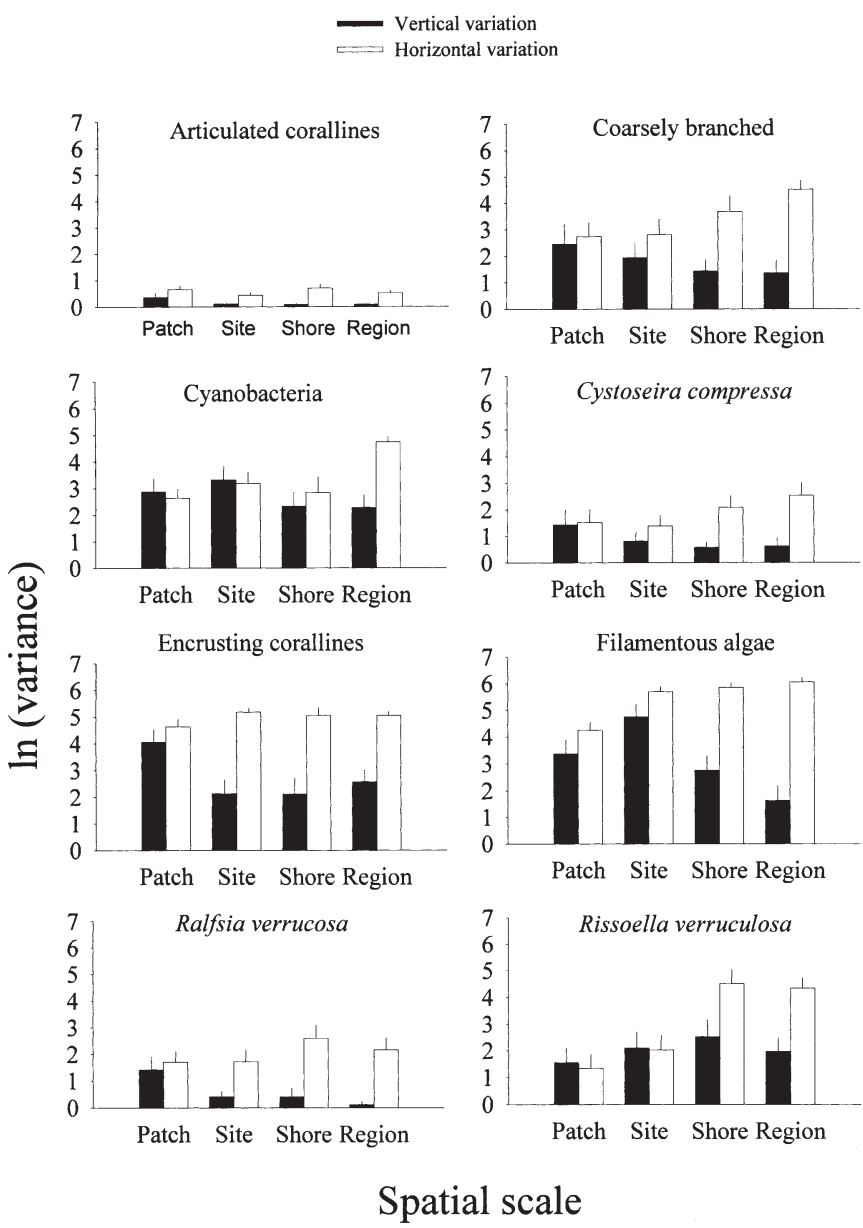

Fig. 2. Mean $(+\mathrm{SE}, \mathrm{n}=18)$ values of vertical and horizontal variability in abundance (in log form) of algae at 4 spatial scales izontal than vertical variability. In none of these analyses was vertical variation larger than horizontal variation.

SNK tests within the Scale $\times$ Type of variability interaction allowed a test of the null hypothesis that horizontal variability was invariant to scale. These analyses revealed no significant change with scale of horizontal variability for coarsely branched algae and encrusting corallines (Fig. 2, Table 3), indicating that most of the variation for these organisms was at the scale of the patch (among quadrats). In contrast, there were significant components of horizontal variability associated with the scales of the site, the shore and the region for filamentous algae, Rissoella verruculosa and cyanobacteria, respectively (Fig. 2, Table 3). The relative contribution of small-scale spatial variation (among quadrats within patches) was large for these organisms (Fig. 2). A similar pattern was evident for articulate corallines, although the SNK test could not discriminate any alternative to the null hypothesis in this case (Fig. 2, Table 3).

The second outcome of this analysis consisted in a significant main effect of Type of variability for Cystoseira compressa and Ralfsia verrucosa. Horizontal variance was significantly larger than vertical variation at any scale for these species (Fig. 2). In contrast, the main effect of Scale was not significant, indicating that most of the variation was among quadrats and no extra variance was added by scales larger than that of the patch for these species.

Patterns similar to those described for macroalgae were observed for invertebrates. Significant interactions between Scale and Type of variability occurred 
Table 3. Results of SNK tests within the Type of variability $\times$ Scale interactions in Table 2. Pa: patch, Si: site, Sh: shore, Re: region, na: no specific alternative to the null hypothesis could be identified

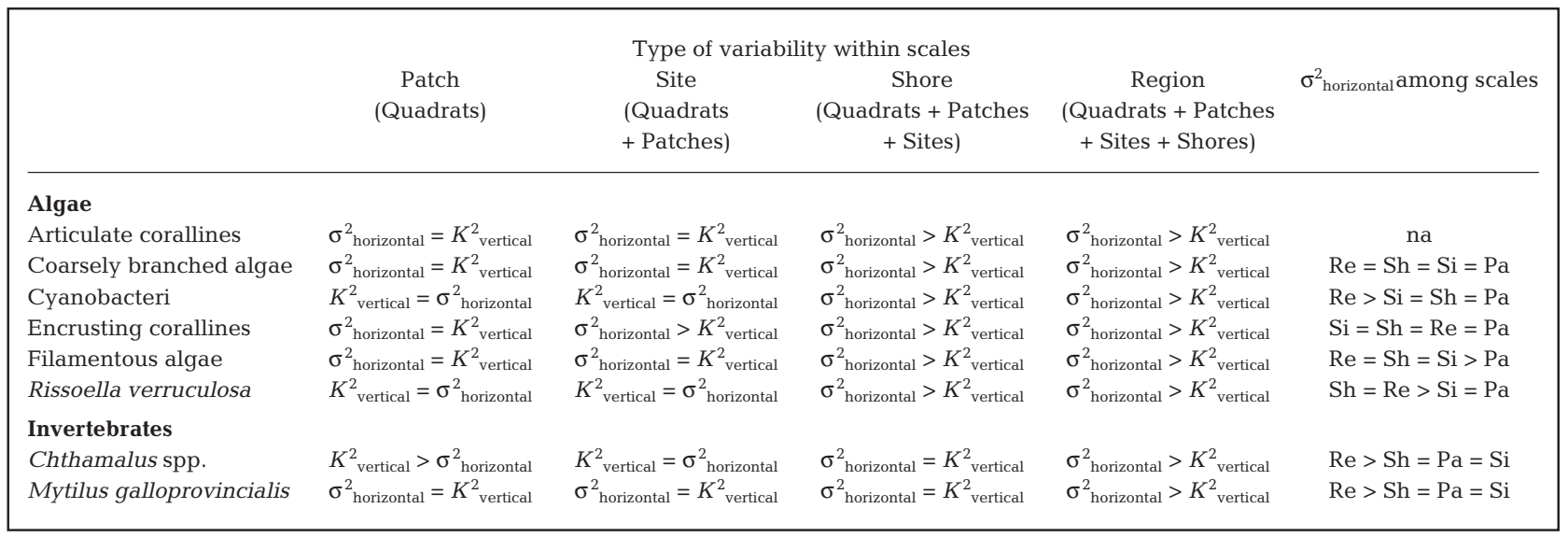

for Chthamalus spp. and Mytilus galloprovincialis (Fig. 3, Table 2). SNK tests indicated that variability in abundance was significantly larger vertically than horizontally at the scale of the patch for barnacles, while the opposite pattern occurred at the regional scale (Table 3). No significant difference between vertical and horizontal variation was observed for mussels at spatial scales ranging from the scale of the patch to that of the shore, while at the regional scale horizontal variability was significantly larger than vertical variability (Table 3). Two relevant scales of horizontal variation were detected for these invertebrates: the scale of the patch and the regional scale (Fig. 3, Table 3).
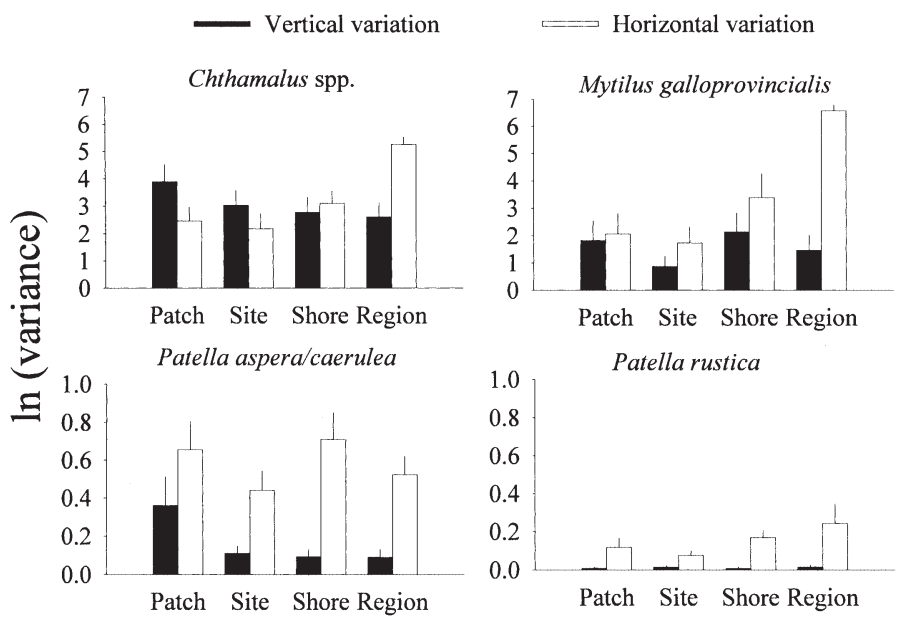

\section{Spatial scale}

Fig. 3. Mean $(+\mathrm{SE}, \mathrm{n}=18)$ values of vertical and horizontal variability in abundance (in log form) of invertebrates at 4 spatial scales. Note that the variability is expressed on a different scale for Patella spp.
A significant main effect of Type of variability occurred for the limpets Patella aspera/caerulea (these species could not be distinguished easily in the field and were lumped together) and P. rustica. Horizontal variability was significantly larger than vertical variation at any scales for both taxa (Fig. 3, Table 2). In neither case was there a main effect of Scale, indicating that most of the variation was among quadrats and that there was no extra-variability associated with scales larger than that of the patch (Fig. 3).

Multivariate analyses of spatial variation from abundance data revealed a highly significant Scale $\times$ Type of variation interaction $\left(\mathrm{MS}_{\text {effect }}=20.29, \mathrm{MS}_{\text {resid- }}\right.$ ual $=0.97, F_{3,136}=21.0, \mathrm{p}<0.0001$; variances were heterogeneous in this analysis: Cochran's $C$ test $=$ $0.81, \mathrm{p}<0.01)$. SNK tests within this interaction indicated that vertical variation was significantly larger than horizontal variability at the scale of the patch and that of the site, no significant difference occurred at the scale of the shore, while there was significantly more horizontal than vertical variation at the regional scale (Fig. 4). Frequency distributions of estimates of multivariate variation clearly indicated the increasing importance of horizontal variability at increasing spatial scales (Fig. 5). The SNK test comparing horizontal variances at different scales could not identify any specific alternative to the null hypothesis. The relative importance of small-scale spatial variation (among quadrats within patches) was, however, more important than the contribution of any other spatial scale (Fig. 4). Exactly the same results were obtained from presence/absence data (not shown), suggesting that multivariate patterns were driven by changes in taxonomic composition of assemblages rather than by variation in relative abundance of taxa. 


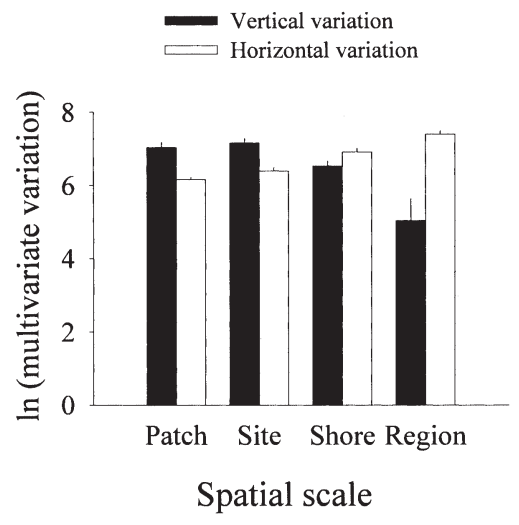

Fig. 4. Mean $(+\mathrm{SE}, \mathrm{n}=18)$ values of vertical and horizontal multivariate variation (in $\log$ form) at 4 spatial scales. Bray-Curtis measures of dissimilarity calculated from quantitative data on abundance of taxa. Same results obtained from presence/absence data, not shown (see text for further details)

\section{DISCUSSION}

The results of this study indicate that any description of spatial pattern in abundance for organisms living on rocky sea shores in the NW Mediterranean must include both vertical and horizontal sources of variation regardless of the scale investigated. Most of the univariate analyses indicated either no difference between vertical and horizontal spatial variability, or significantly more horizontal variation at the scales of the patch and the site. Horizontal variability was generally larger than vertical variation at the scale of the shore or the regional scale. These results support a model of spatial distribution of organisms on rocky shores where horizontal variability is at least as important as vertical variability at any scales (Model 3 in Table 1). In contrast, multivariate analyses showed significantly more vertical than horizontal variation at the scales of the patch and the site, while the opposite was evident at the regional scale (supporting Model 2 in Table 1). The results also indicated that much of the variation occurred among quadrats within patches for all the taxa considered. Variation among patches was significant for filamentous algae, while sites added a significant component of variation for Rissoella verruculosa; changes at the regional scale were important for coarsely branched algae, Chthamalus spp. and Mytilus galloprovincialis. Horizontal variation was large among quadrats within patches for whole assemblages, other spatial scales adding nothing in terms of multivariate variability.

The analysis of spatial pattern of biological variables along environmental gradients has a long tradition in terrestrial (e.g. Greig-Smith 1952, Kershaw 1957,
Hoagland \& Collins 1997) and aquatic ecology (e.g. Stephenson \& Stephenson 1949, Chapman 1974, Grassle et al. 1975). These studies have provided the observational background for experimental analyses on causal processes, including competition (Lubchenco 1980, Keddy 1984), the effect of consumers (Paine 1974, Menge \& Sutherland 1987), physical factors (Wesser \& Armbruster 1991) and, less frequently, the interplay between physical and biological processes (Bertness 1991, Benedetti-Cecchi et al. 2000a). Because the aim of these studies was to explain variation along environmental gradients, they correctly focussed on processes that were likely mechanisms
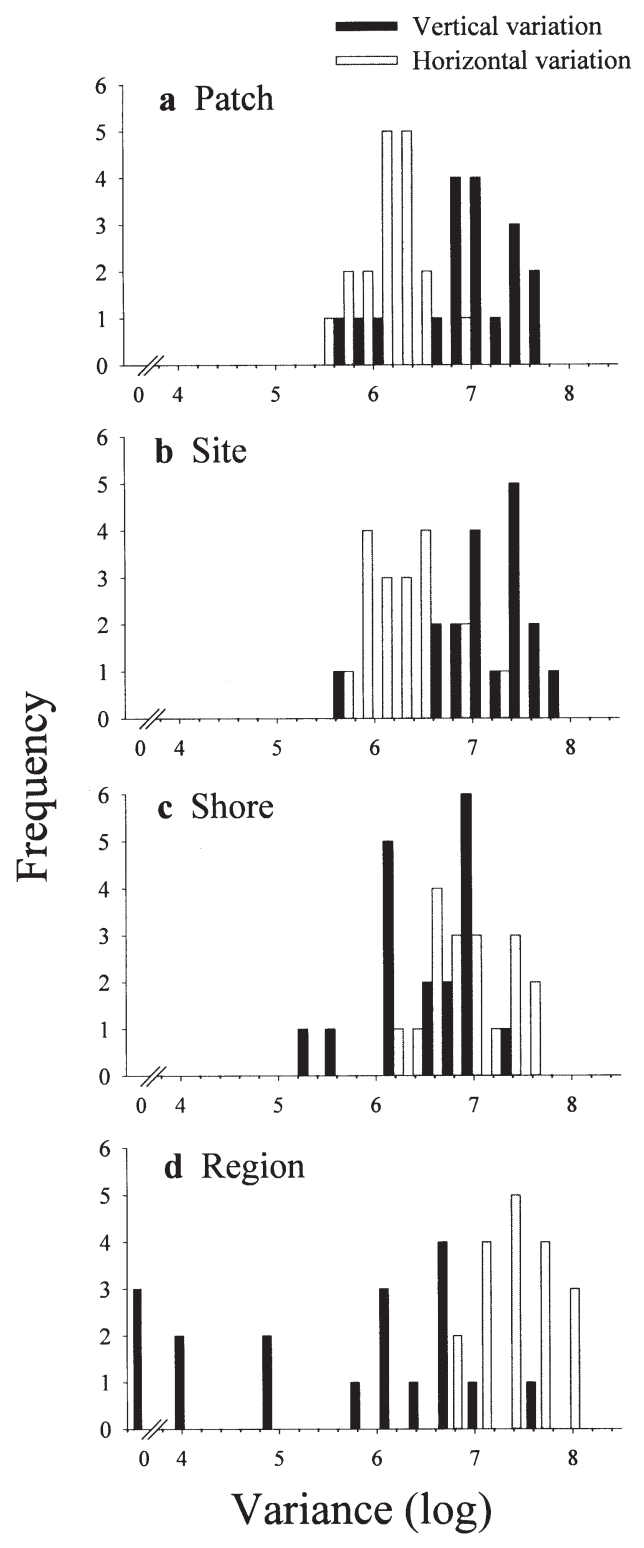

Fig. 5. Frequency distributions of estimates of vertical and horizontal multivariate variation at 4 spatial scales 
explaining the original observation. Descriptive studies of spatial pattern along environmental gradients, however, have rarely provided comparative estimates of variation among sampling units within strata at the appropriate spatial scales. The increasing evidence pointing to the importance of spatial patchiness and the hierarchical nature of spatial variability in assemblages suggests that variation within strata is important (Pickett \& White 1985, Kotliar \& Wiens 1990, Levin 1992, Horne \& Schneider 1995, Underwood \& Chapman 1996, this study). This finding raises an important question: Are there distinct processes responsible for spatial variation within strata, or are the processes underlying variability along environmental gradients similar to those generating patchiness and hierarchical structure in assemblages?

Although the present study did not investigate causal processes explicitly, the patterns described here and in previous experimental work may provide some clues on the causes of spatial variation in the northwest Mediterranean. Pre-emption of the substratum by dominant organisms (e.g. barnacles, Rissoella verruculosa, turf-forming/encrusting algae) is known to account for some of the variation across the vertical gradient of the shore (Benedetti-Cecchi et al. 1999). This result was not surprising and corroborated the findings of many other studies on rocky shores, reporting competition as a prominent process maintaining differences in the structure of assemblages among tidal heights (e.g. Schonbeck \& Norton 1978, Foster 1982, Hawkins \& Harkin 1985). Benedetti-Cecchi et al. (1999) also found that the magnitude of interactions among organisms living at different heights on the shore was consistent among sites 10s to 100 s of m apart (with the notable exception of $R$. verruculosa, see below). Consistent effects were also found in correspondence to the upper and lower borders of the dominant organisms, indicating that pre-emption of the substratum was independent of physical stress or any other process that might have changed with height on the shore. This contrasts with the general view that the upper limits of distribution of intertidal organisms are set by physical factors, while lower limits are determined by biological interactions (Connell 1972, Hawkins et al. 1992).

Although the effect size of these interactions was generally large (removal of dominant organisms often resulted in a $100 \%$ increase in abundance of other species), pre-emption of the substratum alone could not explain all the variation across the vertical gradient of the shore (Benedetti-Cecchi et al. 1999). Similarly, grazing by limpets, another potentially important process maintaining vertical patterns of distribution of organisms on rocky shores (Underwood \& Jernakoff 1981, Hawkins \& Hartnoll 1983), explained only a small proportion of the differences in cover between high-shore and low-shore algae (Benedetti-Cecchi et al. 2000a). These effects were consistent among sites 100 s to 1000 s of $m$ apart but differed among shores $100 \mathrm{~s}$ of $\mathrm{km}$ apart. In contrast to the highly variable and generally weak effects of limpets, physical factors such as slope of the substratum were important in maintaining differences between mid-shore and low-shore assemblages. Aspect of the substratum was also important in generating spatial variability among patches of habitat within tidal heights on these shore (BenedettiCecchi 2000). For example, patches of horizontal substrata offered an unsuitable habitat for Rissoella verruculosa, presumably due to the retention of sea water, while they supported dense stands of filamentous algae (Benedetti-Cecchi 2000). $R$. verruculosa was more abundant on emergent rocks or on sub-horizontal substrata. Therefore, spatial heterogeneity in the physical features of the habitat could generate spatial variation in abundance of organisms regardless of tidal height. Collectively, these results indicated that physical processes generated small-scale vertical and horizontal spatial variation for some species, while biological interactions operated mainly across the vertical gradient. For rocky shores in the Mediterranean, where the amplitude of the tide is small and topographic complexity is generally high, models that focus attention on physical factors may have large heuristic power to explain both vertical and horizontal spatial variation. The relationships among topographic complexity, retention of sea water and horizontal spatial variation in populations and assemblages are currently under investigation.

Chthamalus spp. was the only organism that exhibited more variation vertically than horizontally at small spatial scales. Variation among tidal heights was significantly larger than horizontal variability at the scale of the patch for these organisms. Previous studies have shown that pre-emption of the substratum and postrecruitment mortality due to unknown processes can account for the decline in cover of barnacles from the top to the bottom of the shore (Benedetti-Cecchi et al. 1999, 2000b). Variation in recruitment might also contribute to these differences, as observed elsewhere (Grosberg 1982).

Patterns in assemblages were significantly more variable vertically than horizontally at small spatial scales. This result is consistent with the findings of other studies of rocky shores indicating large differences in the structure of assemblages from the top to the bottom of the shore (e.g. Southward 1958, Lewis 1964). However, the relationship between vertical and horizontal variation was not scale independent. These sources of variation were similar at the scale of the shore, indicating that different assemblages may also 
occur within any tidal height when considering different sites on the same coast. Differences among assemblages within tidal heights were even larger, and significantly larger than vertical variation, when considering different shores.

Interpretation of multivariate patterns such as those illustrated here is complicated by the large number of processes that may potentially regulate the structure of assemblages. Multivariate patterns may originate from changes in the relative abundance of species (or higher taxa), changes in species composition, or both. These changes reflect the influence of processes affecting the distribution and abundance of each species in an assemblage and the direct and indirect effects of interactions among species (Wotton 1994, Menge 1995, Benedetti-Cecchi 2000). In the present study, multivariate analyses on quantitative estimates of abundance of taxa produced the same results as those on presence/absence data. This suggested that patterns were governed primarily by compositional changes in assemblages, both horizontally and vertically on the shore. The same factors already discussed as potentially important for single species or groups of species (see above), can explain spatial variation in assemblages. In fact, a previous study indicated that the difference between mid-shore and low-shore assemblages was more evident on vertical than horizontal substrata, highlighting the importance of physical factors (Benedetti-Cecchi et al. 2000a). The same study also reported that limpets accounted for $20 \%$ of the differences between mid-shore and low-shore assemblages, indicating that the signal of biological processes is not lost when examining patterns in assemblages. Why these or any other process contributing to multivariate variation produced more variability vertically than horizontally remains unknown.

In a previous study on the distribution of algae and invertebrates on rocky coasts in the northwest Mediterranean, Menconi et al. (1999) found considerable variation in vertical patterns of abundance between 2 shores about $70 \mathrm{~km}$ apart and among sites within tidal heights 10 s to 100 s of $\mathrm{m}$ apart. This earlier study was not specifically designed to compare the magnitude of vertical and horizontal spatial variability, although it provided some preliminary indication that the 2 sources of variation were of similar importance. In the present study, meaningful comparisons of vertical variability with horizontal variation in abundance were possible. The sampling design developed here allowed comparisons of independent estimates for each of the 2 types of variability at each scale of horizontal spatial variation. Comparing measures of actual variability has several advantages over the alternative of expressing the magnitude of ecological effects as percentages of explained variation in hierarchical
ANOVA models. Underwood \& Petraitis (1993) and Underwood (1996) discussed several shortcomings of this approach, including the problem of introducing non-independence when expressing components of variation as percentages, and difficulties in interpreting percentages of variation in mixed models due to the confounding effect of mixing true estimates of variability with the effect size of fixed terms in the model. In any hierarchical sampling design done only once, there is the additional problem that variability is measured more precisely at small than large spatial scales, because there are more degrees of freedoms associated with terms low in the hierarchy. The procedure adopted in the present study obviated the problems of non-independence and precision of measures of variation, but did not solve the problem of comparing true variances (horizontal variability) with fixed effects (the terms measuring vertical variation). This probably had only a minor impact on the study, because the focus was on the relationship between the 2 types of variability across different spatial scales, rather than an absolute comparison between vertical and horizontal variation. Future studies, however, should be designed to address this issue more specifically.

When properly replicated, hierarchical analyses of spatial variability can provide some clues to the range of processes that may be most important to organisms. Horne \& Schneider (1995) discussed the assumptions inherent in matching scales of biological pattern to physical and/or biological processes that may operate at the same scales, for a variety of terrestrial and aquatic systems. A particularly important assumption of this approach is that the coupling of pattern with process occurs at a characteristic scale. This, however, is a critical assumption only when causal processes are inferred from the observed patterns without any further scrutinity. In any structured research programme, the detection of pattern is preliminary to further experimental tests aimed at identifying causal processes. The identification of characteristic scales of spatial (or temporal) variation can focus attention on some processes and exclude others as very unlikely explanations for the observed patterns. It is difficult to imagine any single process that can generate variation across a wide range of spatial scales. In general, different sets of processes account for spatial variation at very different scales. For example, large-scale oceanographic processes influencing primary productivity can explain large-scale differences in biomass of intertidal invertebrates on rocky shores in South Africa (Bustamante et al. 1995a,b). In contrast, behaviour can account for small-scale spatial patterns of distribution of intertidal invertebrates in New South Wales (Chapman 1995, Underwood \& Chapman 1996). However, the possibility for spatial variability generated at a particular scale 
to propagate at larger or smaller spatial scales cannot be excluded (Schneider 1994, Horne \& Schneider 1995).

Characteristic scales of spatial variation were detected for a number of taxa in the present study. Variation among quadrats $10 \mathrm{~s}$ of $\mathrm{cm}$ apart was important for all organisms. The physical and biological factors that were likely to contribute to small-scale variation have already been discussed. In addition to small-scale spatial patterns, there was a significant component of horizontal variability due to sites (the scale of the shore) for Rissoella verruculosa. Interestingly, $R$. verruculosa was the only organism in Benedetti-Cecchi et al. (1999) that exhibited inconsistent patterns of interaction with other sessile organisms in the assemblage across sites $10 \mathrm{~s}$ to $100 \mathrm{~s}$ of $\mathrm{m}$ apart. Thus, pre-emption of the substratum may account for some of the variation in abundance of $R$. verruculosa among sites on a shore. Other potentially important processes that can explain spatial variability at this scale, such as variation in recruitment (e.g. Menge et al. 1993) and the requirements for habitat, are currently under investigation. These results were not confounded by temporal variability because the only scale at which this might have occurred was at the regional scale, where no variation was observed for $R$. verruculosa.

In contrast to Rissoella verruculosa and the other macroalgae, there was a significant component of spatial variance associated with shores (the regional scale) for cyanobacteria, Chthamalus spp. and Mytilus galloprovincialis. Regional patterns were largely due to the low abundance of cyanobacteria and barnacles at Punta Bianca, the northernmost shore in the study, which also supported more mussels than the other shores. In a previous study, Benedetti-Cecchi et al. (2000b) found considerably more variation in patterns of growth of barnacles among shores $10 \mathrm{~s}$ to $100 \mathrm{~s}$ of $\mathrm{km}$ apart than among quadrats $10 \mathrm{~s}$ of $\mathrm{cm}$ apart. There was also considerable variability in recruitment of barnacles at the regional scale, although recruitment was much more variable among quadrats. No comparable information was available for mussels. These patterns might be explained in terms of large-scale differences in oceanographic conditions and climate influencing the recruitment and growth of organisms. Punta Bianca is located in one of the most productive areas of the Mediterranean, the Ligurian Sea, and has a peculiar microclimate with cooler waters and lower atmospheric temperatures compared to locations $10 \mathrm{~s}$ of $\mathrm{km}$ toward the south. These characteristics are largely due to the influence of an upwelling system and the closeness to an estuary (Cruzado 1985, Estrada et al. 1985).

Several of the taxa investigated showed a tendency for decreased vertical variability at increasing scales of horizontal spatial variation. In most cases the main change occurred from the scale of the patch to that of the site. None of the models being investigated predicted such changes, for which I have no solid explanation. Possibly, taxa peaked in abundance at different heights on the shore in different patches, so that a wide range of abundances was sampled at any single height when replicate plots were spread along several metres of the shore. As a result, average values should be more similar across heights when sampling encompassed several patches than when it was done entirely within a single patch. This, however, should have been paralleled by an increase in horizontal spatial variance from the scale of the patch to that of the site, a pattern that occurred only occasionally. More research is obviously needed to clarify this point.

The extent to which the patterns of variation documented in the present study can be expected to occur on other rocky sea shores, and particularly in macrotidal environments, remains to be investigated. As discussed throughout, however, patchiness and the hierarchical nature of spatial variability are intrinsic properties of many habitats. This suggests that any investigation of the distribution of populations and assemblages along environmental gradients should be integrated with a hierarchical analysis of spatial variation to fully represent the complexity of natural systems. Failure to recognise this may detract attention from potentially important causal processes, hindering progress in ecological understanding. In this study, I have shown that the magnitude of vertical and horizontal spatial variability was fairly similar at small scales. That is, about $50 \%$ of the variation would have been lost had the study focused on vertical patterns only, and even more variation would have gone undetected at scales larger that that of the patch. More importantly, in the absence of any evidence for the relevance of horizontal variability, there would have been no observational basis for discussing causes of spatial variation other than those commonly invoked to explain the vertical distribution of organisms on rocky sea shores. The challenge now is to explain the patterns of interaction between vertical and horizontal variability in terms of the underlying causal processes (Underwood \& Petraitis 1993, Horne \& Schneider 1995).

Acknowledgements. I sincerely thank R. Coleman and F. Micheli for their criticism on an early draft of this manuscript. Comments from M. G. Chapman, S. J. Hawkins and an anonymous reviewer greatly improved the final version. Part of the manuscript was written during a sabbatical at the Centre for Research on Ecological Impacts of Coastal Cities, University of Sydney. I thank A. J. Underwood and M. G. Chapman for their kind hospitality and support during my stay in Sydney. This study was supported by the European Community under MAST Programme MAS3-CT95-0012 (EUROROCK) and by a grant from the University of Pisa. 


\section{LITERATURE CITED}

Anderson MJ (2001) A new method for non-parametric multivariate analysis of variance. Aust Ecol 26:32-46

Archambault P, Bourget E (1996) Scales of coastal heterogeneity and benthic intertidal species richness, diversity and abundance. Mar Ecol Prog Ser 136:111-121

Bell G, Lechowicz MJ, Appenzeller A, Chandler M, DeBlois E, Jackson L, Mackenzie B, Preziosi R, Schallenberg M, Tinker N (1993) The spatial structure of the physical environment. Oecologia 96:114-121

Benedetti-Cecchi L (2000) Predicting direct and indirect interactions during succession in a midlittoral rocky shore assemblage. Ecol Monogr 70:45-72

Benedetti-Cecchi L, Cinelli F (1997) Spatial distribution of algae and invertebrates in the rocky intertidal zone of the Strait of Magellan: are patterns general? Polar Biol 18: 337-343

Benedetti-Cecchi L, Airoldi L, Abbiati M, Cinelli F (1996) Estimating the abundance of benthic invertebrates: a comparison of procedures and variability between observers. Mar Ecol Prog Ser 138:93-101

Benedetti-Cecchi L, Menconi M, Cinelli F (1999) Pre-emption of the substratum and the maintenance of spatial pattern on a rocky shore in the northwest Mediterranean. Mar Ecol Prog Ser 181:13-23

Benedetti-Cecchi L, Bulleri F, Cinelli F (2000a) The interplay of physical and biological factors in maintaining midshore and low-shore assemblages on rocky coasts in the north-west Mediterranean. Oecologia 123:406-417

Benedetti-Cecchi L, Acunto S, Bulleri F, Cinelli F (2000b) Population ecology of the barnacle, Chthamalus stellatus (Poli), in the northwest Mediterranean. Mar Ecol Prog Ser 198:157-170

Bertness MD (1991) Zonation of Spartina patens and Spartina alterniflora in a New England salt marsh. Ecology 72: 138-148

Borcard D, Legendre P, Drapeau P (1992) Partialling out the spatial component of ecological variation. Ecology 73: 1045-1055

Bray JR, Curtis JT (1957) An ordination of the upland forest communities of Southern Wisconsin. Ecol Monogr 27: 325-349

Burdick RK, Graybill FA (1992) Confidence intervals on variance components. Marcel Dekker, New York

Bustamante RH, Branch GM, Eekhout S, Robertson B, Zoutendyk P, Schleyer M, Dye A, Hanekom N, Keats D, Jurd M, McQuaid CD (1995a) Gradients of intertidal primary productivity around the coast of South Africa and their relationships with consumer biomass. Oecologia 102: 189-201

Bustamante RH, Branch GM, Eekhout S (1995b) Maintenance of an exceptional intertidal grazer biomass in South Africa: subsidy by subtidal kelps. Ecology 76: 2314-2329

Carroll SS, Pearson DL (1998) The effects of scale and sample size on the accuracy of spatial predictions of tiger beetle (Cicindelidae) species richness. Ecography 21:401-414

Chapman MG (1995) Aggregation of the littorinid snail Littorina unifasciata in New South Wales, Australia. Mar Ecol Prog Ser 126:191-202

Chapman VJ (1974) Salt marshes and salt deserts of the world. J Cramer, Lehre

Connell JH (1972) Community interactions on marine rocky intertidal shores. Annu Rev Ecol Syst 4:169-192

Cressie NAC (1993) Statistics for spatial data. John Wiley \& Sons Inc, New York
Cruzado A (1985) Chemistry of Mediterranean waters. In: Margalef R (ed) Western Mediterranean. Pergamon Press, Oxford, p 126-147

Dayton PK, Tegner MJ (1984) The importance of scale in community ecology: a kelp forest example with terrestrial analogs. In: Price PW, Slobodchikoff CN, Gand WS (eds) A new ecology: novel approaches to interactive systems. John Wiley \& Sons Inc, New York, 457-481

Dethier MN, Graham ES, Cohen S, Tear LM (1993) Visual versus random-point percent cover estimations: 'objective' is not always better. Mar Ecol Prog Ser 96:93-100

Estrada M, Vives F, Alcarez M (1985) Life and the productivity of the open sea. In: Margalef R (ed) Western Mediterranean. Pergamon Press, Oxford, p 148-197

Foster MS (1982) Factors controlling the intertidal zonation of Iridaea flaccida (Rhodophyta). J Phycol 18:285-294

Foster MS (1990) Organization of macroalgal assemblages in the Northeast Pacific: the assumption of homogeneity and the illusion of generality. Hydrobiologia 192:21-33

Gaston KJ, McArdle BH (1993) Measurement of variation in the size of populations in space and time: some points of clarification. Oikos 68:357-360

Grassle JF, Sanders HL, Hessler RR, Rowe GT, McLellan T (1975) Pattern and zonation: a study of the bathyal magafauna using the research submersible Alvin. Deep-Sea Res 22:457-481

Greig-Smith P (1952) The use of random and contiguous quadrats in the study of the structure of plant communities. Ann Bot 16:293-316

Grosberg RK (1982) Intertidal zonation of barnacles: the influence of planktonic zonation of larvae on vertical distribution of adults. Ecology 63:894-899

Hawkins SJ, Hartnoll RG (1983) Grazing of intertidal algae by marine invertebrates. Oceanogr Mar Biol Annu Rev 21: 195-282

Hawkins SJ, Harkin E (1985) Preliminary canopy removal experiments in algal dominated communities low on the shore and in the shallow subtidal on the Isle of Man. Bot Mar 28:223-230

Hawkins SJ, Hartnoll RG (1985) Factors determining the upper limits of intertidal canopy-forming algae. Mar Ecol Prog Ser 20:265-271

Hawkins SJ, Hartnoll RG, Kain JM, Norton TA (1992) Plantanimal interactions on hard substrata in the north-east Atlantic. In: John DM, Hawkins SJ, Price JH (eds) Plantanimal interactions in the marine benthos. Systematics Association Spec Vol 46, Clarendon Press, Oxford, p 1-32

Hewitt JE, Thrush SF, Cummings VJ, Turner SJ (1998) The effect of changing sampling scales on our ability to detect effects of large-scale processes on communities. J Exp Mar Biol Ecol 227:251-264

Hoagland BW, Collins SL (1997) Gradient models, gradient analysis, and hierarchical structure in plant communities. Oikos 78:23-30

Horne JK, Schneider DC (1995) Spatial variability in ecology. Oikos 74:18-26

Hurlbert SH (1984) Pseudoreplication and the design of ecological field experiments. Ecol Monogr 54:187-211

Istituto Idrografico della Marina (1995) Tavole di marea. IIM, Genova

Keddy PA (1984) Plant zonation on lakeshores in Nova Scotia: a test of the resource specialization hypothesis. J Ecol 72: 797-808

Kershaw KA (1957) The use of cover and frequency in the detection of pattern in plant communities. Ecology 38: 291-299

Kotliar NB, Wiens JA (1990) Multiple scales of patchiness and 
patch structure: a hierarchical framework for the study of heterogeneity. Oikos 59:253-260

Lapointe L, Bourget E (1999) Influence of substratum heterogeneity scales and complexity on a temperate epibenthic marine community. Mar Ecol Prog Ser 189:159-170

Legendre P, Anderson MJ (1999) Distance-based redundancy analysis: testing multispecies responses in multifactorial ecological experiments. Ecol Monogr 69:1-24

Levin SA (1992) The problem of pattern and scale in ecology. Ecology 73:1943-1967

Lewis JR (1964) The ecology of rocky shores. English University Press, London

Lubchenco J (1980) Algal zonation in the New England rocky intertidal community: an experimental analysis. Ecology 61:333-344

McArdle BH, Anderson MJ (2001) Fitting multivariate models to community data: a comment on distance-based redundancy analysis. Ecology 82:290-297

McCook LJ (1994) Understanding ecological community succession: causal models and theories, a review. Vegetatio 110:115-147

Menconi M, Benedetti-Cecchi L, Cinelli F (1999) Spatial and temporal variability in the distribution of algae and invertebrates on rocky shores in the northwest Mediterranean. J Exp Mar Biol Ecol 233:1-23

Menge BA (1995) Indirect effects in marine rocky intertidal interaction webs: patterns and importance. Ecol Monogr 65:21-74

Menge BA, Olson AM (1990) Role of scale and environmental factors in regulation of community structure. Trends Ecol Evol 5:52-57

Menge BA, Sutherland JP (1987) Community regulation: variation in disturbance, competition, and predation in relation to environmental stress and recruitment. Am Nat 130: 730-757

Menge BA, Farrell TM, Olson AM, Van Tamelen PG, Turner $\mathrm{T}$ (1993) Algal recruitment and the maintenance of a plant mosaic in the low intertidal region on the Oregon coast. J Exp Mar Biol Ecol 170:91-116

Paine RT (1974) Intertidal community structure: experimental studies on the relationship between a dominant competitor and its principal predator. Oecologia 15:93-120

Pickett STA, White PS (1985) The ecology of natural disturbance and patch dynamics. Academic Press, Orlando

Rakocinski CF, LeCroy SE, McLelland JA, Heard RW (1998) Nested spatiotemporal scales of variation in sandy-shore macrobenthic community structure. Bull Mar Sci 63: $343-362$

Rossi RE, Mulla DJ, Journel AG, Franz EH (1992) Geostatistical tools for modeling and interpreting ecological spatial dependence. Ecol Monogr 62:277-314

Schonbeck MW, Norton TA (1978) Factors controlling the upper limits of fucoid algae on the shore. J Exp Mar Biol Ecol 31:303-313

Schneider DC (1994) Quantitative ecology: spatial and temporal scaling. Academic Press, San Diego

Schoch GC, Dethier MN (1996) Scaling up: the statistical link-

Editorial responsibility: Otto Kinne (Editor),

Oldendorf/Luhe, Germany age between organismal abundance and geomorphology on rocky intertidal shorelines. J Exp Mar Biol Ecol 201: $37-72$

Searle SR, Casella G, McCulloch CE (1992) Variance components. Wiley, New York

Southward AJ (1958) The zonation of plants and animals on rocky sea shores. Biol Rev 33:137-177

Stephenson TA, Stephenson A (1949) The universal feature of zonation between tide-marks on rocky coasts. J Ecol 37: 289-305

Thrush SF (1999) Complex role of predators in structuring soft-sediment macrobenthic communities: implications of changes in spatial scale for experimental studies. Aust J Ecol 24:344-354

Underwood AJ (1985) Physical factors and biological interactions: the necessity and nature of ecological experiments. In: Moore PG, Seed R (eds) The ecology of rocky coasts. Hodder \& Stoughton, London, p 372-390

Underwood AJ (1996) Spatial patterns of variability in density of intertidal populations. In: Floyd RB, Sheppard AW, De Barro PJ (eds) Frontiers of population ecology. CSIRO Publishing, Melbourne, pp 369-389

Underwood AJ (1997) Experiments in ecology: their logical design and interpretation using analysis of variance. Cambridge University Press, Cambridge

Underwood AJ, Chapman MG (1996) Scales of spatial patterns of distribution of intertidal invertebrates. Oecologia 107:212-224

Underwood AJ, Chapman MG (1998) A method for analysing spatial scales of variation in composition of assemblages. Oecologia 117:570-578

Underwood AJ, Jernakoff P (1981) Effects of interactions between algae and grazing gastropods on the structure of a low-shore intertidal algal community. Oecologia 48:221-233

Underwood AJ, Petraitis PS (1993) Structure of intertidal assemblages in different locations: how can local processes be compared? In: Ricklefs R, Schutler D (eds) Species diversity in ecological communities. University of Chicago Press, Chicago, p 38-51

Wesser SD, Armbruster WS (1991) Species distribution controls across a forest-steppe transition: a causal model and experimental test. Ecol Monogr 61:323-342

Wiens JA, Stenseth NC, Van Horne B, Ims RA (1993) Ecological mechanisms and landscape ecology. Oikos 66: $369-380$

Wootton JT (1994) The nature and consequences of indirect effects in ecological communities. Annu Rev Ecol Syst 25: 443-466

Winer BJ, Brown DR, Michels KM (1991) Statistical principles in experimental design, 3rd edn. McGraw-Hill, New York

Wu J, Loucks OL (1995) From balance of nature to hierarchical patch dynamics: a paradigm shift in ecology. Q Rev Biol 70:439-466

Zhang ZQ, Sanderson JP (1997) Patterns, mechanisms and spatial scale of aggregation in generalist and specialist predatory mites (Acari: Phytoseiidae). Exp Appl Acarol 21: 393-404

Submitted: August 4, 2000; Accepted: January 17, 2001

Proofs received from author(s): May 11, 2001 